\title{
Selection of Peat Firefighting Foam from Palm Oil Fatty Acid Saponification with Simple Additive Weighting (SAW) Method
}

\author{
Purwo Subekti ${ }^{1,2^{*}}$, Erliza Hambali ${ }^{3,5}$, Ani Suryani ${ }^{3,5}$, Prayoga Suryadarma ${ }^{3}$, Bambang Hero \\ Saharjo ${ }^{4}$, Mira Rivai ${ }^{5}$
}

\author{
1Sekolah Pascasarjanan, Program Studi Teknologi Industri Pertanian, Institut Pertanian Bogor - Bogor \\ 2Program Studi Teknik Mesin, Fakultas Teknik, Universitas Pasir Pengaraian - Rokan Hulu, Riau \\ 3Departemen Teknologi Industri Pertanian, Fakultas Teknologi Pertanian, Institut Pertanian Bogor - Bogor \\ ${ }^{4}$ Departemen Silvikultur, Fakultas Kehutanan, Institut Pertanian Bogor - Bogor \\ ${ }^{5}$ Pusat Penelitian Surfaktan dan Bioergi Institut Pertanian Bogor - Bogor
}

*Corresponding author: purwos73@gmail.com

\begin{abstract}
Fire suppression on peatlands requires large amounts of water and a longer time, hence it is necessary to develop extinguishing material that needs less water and time. Thus the negative impact of the fire can be solved immediately. One alternative for fire suppression that saves water and time is the application of foaming agents as an extinguishing material. This study aims to select the raw material of foaming agent from palm oil fatty acid saponification using the SAW method. Analysis results revealed that the best raw materials were sodium laurate and potassium palmitate, with the highest weight values of 70, 08 and 53, 87. Both of these materials have complementary properties. Sodium laurate can produce a lot of foam and reduce large surface tension. Potassium Palmitate produces the foam which can last the longest so that with the formulation of the two ingredients it is expected to produce foam that can extinguish peat fires.

Abstrak. Pemadaman kebakaran gambut membutuhkan banyak air dan waktu yang lama, sehingga perlu adanya usaha untuk pengembangan pemadaman dengan menghemat air dan waktu lebih cepat sehingga dampak negatif dari kebakaran dapat segera teratasi. Salah satu alternatif untuk pemadaman yang hemat air dan mengurangi waktu pemadaman adalah penggunaan foaming agent sebagi media pemadam. Tujuan dari penelitian ini adalah untuk memilih bahan baku foaming agent dari hasil saponifikasi fatty acid minyak sawit dengan metode SAW. Dari hasil analisis dihasilkan bahan baku yang terbaik adalah natrium laurat dan potasium palmitat. Kedua bahan tersebut memiliki sifat yang saling melengkapi, natrium laurat mampu menghasilkan busa yang banyak dan menurunkan tegangan permukaan yang besar. Sementara itu, potasium palmitat menghasilkan busa yang mampu bertahan paling lama, sehingga dengan formulasi kedua bahan tersebut diharapkan mampu menghasilkan busa yang dapat memadamkan kebakaran gambut.
\end{abstract}

Kata kunci: minyak sawit, gambut, SAW, foaming agent, busa.

(C) 2018. BKSTM-Indonesia. All rights reserved

\section{Pendahuluan}

Usaha untuk mengurangi penggunaan air dan mempercepat waktu pemadaman kebakaran lahan gambut terus di lakukan, salah satunya adalah penggunaan foaming agent sebagi media pemadam. Selain mempercepat proses pemadaman, penggunaan busa juga akan menghemat air sehingga pemadaman bisa dilakukan ke daerah yang lebih luas [1-3]. Selain membentuk busa, foaming agent berfungsi untuk menurunkan tegangan permukaan air, sehingga selain tidak mudah menguap cairan fiaming agent mampu menembus pori-pori permukaan yang terbakar [4, 5]. Karena sifat busa yang menutupi dan mendinginkan permukaan areal yang terbakar sehingga asap yang keluar dari pori-pori gambut akan berhenti, dan dengan sendirinya luasan sebaran asap akan berkurang [3]. Selain mampu memadamkan api, produk foaming agent juga di harapkan ramah lingkungan $[3,2,5]$.

Penggunaan foaming agent untuk pemadam kebakaran lahan gambut dari bahan alami berkembang terus, sebagai pengganti bahan sintesis dari turunan minyak bumi yang memiliki kecenderung membutuhkan waktu yang lama untuk terurai ke lingkungan tanah dan air $[4,5]$. Bahan baku foaming agent yang potensial untuk di kembangkan di Indonesia adalah asam lemak yang bersumber dari minyak sawit [5-8].

Foaming agent dihasilkan dari proses saponifikasi fatty acid minyak sawit, setelah saponifikasi dilanjutkan dengan formulasi dengan bahan tambahan lainnya untuk mendapatkan karakteristik busa yang dihasilkan stabil pada waktu di aplikasikan [8]. Tujuan dari penelitian ini 
adalah menganalisis sifat fisik dan pemilihan bahan baku foaming agent yang digunakan sebagai pemadam kebakaran dari hasil saponifikasi fatty acid minyak sawit.

\section{Metode Penelitian}

Penelitian ini diawali dengan seleksi bahan baku foaming agent dari hasil saponifikasi fatty acid minyak sawit. Bahan tersebut meliputi natrium $(\mathrm{Na})$ palmitat, natrium laurat, natrium oleat, potasium (K) palmitat, potasium laurat dan potasium oleat. Masing-masing bahan berbentuk padat, sehingga sebelum foaming agent dianalisis terlebih dahulu di encerkan dengan aquades. Parameter fisik yang dianalisis adalah volume busa, umur busa, tegangan permukaan, tegangan antarmuka, sudut kontak, viskositas dan densitas. Untuk setiap parameter memerlukan sampel uji sebanyak 1 gram, sampel uji dimasukan kedalam tabung erlenmeyer bersama dengan aquades sebanyak $10 \mathrm{ml}$. Pengencean dilakukan dengan hot plate stirrer dengan temperatur $40-70^{\circ} \mathrm{C}$ dan kecepatan pengadukan 200-300 rpm selama 60 menit.

Setelah mendapatkan data analisis, penelitian selanjutnya adalah seleksi formula foaming agent yang terbaik dengan menggunakan metode Fuzzy Simple Additive Weighting (SAW). Metode Fuzzy SAW ini dipilih karena metode ini menentukan nilai bobot untuk setiap kriteria yaitu parameter uji yang nilainya di pilih oleh para pakar [9-12]. Proses perangkingan dilakukan untuk menyeleksi alternatif yang terbaik dari sejumlah alternatif bahan foaming agent yang ada, sehingga diharapkan mendapatkan formula yang mampu membentuk busa sebagai alternatif pemadam kebakaran gambut.

Hasil perankingan didapatkan melalui penjumlahan dari perkalian matriks ternormalisasi dengan nilai bobot vektor sehingga didapatkan nilai yang dipilih sebagai alternatif terbaik sebagai bahan baku foaming agent [10-12].

Formula untuk melakukan normalisasi tersebut adalah sebagai berikut:

$\frac{X_{i j}}{\operatorname{Max} . X_{i j}}$ Jika $j$ adalah atribut keuntungan (benefit)

$\mathrm{R}_{\mathrm{ij}}=\frac{\text { Min. } X_{i j}}{X_{i j}} \quad$ Jika $\mathrm{j}$ adalah atribut biaya (cost)

Dimana untuk $\mathrm{R}_{\mathrm{ij}}$ adalah tingkatan kinerja ternormalisasi dari pilihan alternatif pada atribut $\mathrm{Cj} ; \mathrm{i}=1,2, \ldots, \mathrm{m}$ dan $\mathrm{j}=1,2, \ldots, \mathrm{n}$.

Keterangan :

$\operatorname{Max} X_{\mathrm{ij}} \quad=$ nilai terbesar dari setiap kriteria $\mathrm{i}$.

Min $X_{i j} \quad=$ nilai terkecil dari setiap kriteria $i$.

$\mathrm{X}_{\mathrm{ij}} \quad=$ nilai atribut yang dimiliki dari setiap kriteria.
Benefit = jika nilai terbesar adalah terbaik.

Cost $=$ jika nilai terkecil adalah terbaik.

Nilai preferensi untuk setiap alternatif (vi) diberikan rumus sebagai berikut :

$\mathrm{V}_{i}=\sum_{j=1}^{n} w_{j}=r_{i j}$

Keterangan :

$\mathrm{V}_{\mathrm{i}} \quad$ = rangking untuk setiap alternatif

$W_{\mathrm{j}}=$ nilai bobot rangking (dari setiap kriteria)

$\mathrm{R}_{\mathrm{ij}}=$ nilai rating kinerja ternormalisasi

\section{Hasil dan Pembahasan}

Data pengukuran respon bahan baku foaming agent hasil saponifikasi asam lemak minyak sawit yang di cairkan disajikan pada Table 1, dari tebel tersebut terlihat foaming agent dari $\mathrm{Na}$ Laurat menghasilkan busa terbanyak. Banyaknya busa dihasilkan akan menentukan luasan areal kebakaran gambut yang dipemadamankan, semakin banyak busa yang dihasilkan maka semakin luas areal yang tertutupi busa [2]. Umur busa paling lama adalah dari bahan Kalium Palmitat yang mampu bertahan 16 hari, ketahanan busa perlu diperhatikan karena kemampuan kinerja busa terhadap pengaruh temperatur panas merupakan salah satu yang terpenting [5].

Tabel 1. Hasil uji bahan baku foaing agent

\begin{tabular}{|c|c|c|c|c|c|c|}
\hline \multirow{3}{*}{$\begin{array}{c}\text { Parameter } \\
\text { Uji }\end{array}$} & \multicolumn{6}{|c|}{ Jenis Foaming Agent } \\
\hline & $\mathrm{Na}$ & $\mathrm{Na}$ & $\mathrm{Na}$ & $\mathrm{K}$ & $\mathrm{K}$ & $\mathrm{K}$ \\
\hline & Palmitat & Laurat & Oleat & Palmitat & Laurat & Oleat \\
\hline $\begin{array}{l}\text { Volume Busa } \\
\text { (ml) }\end{array}$ & 1,33 & 8,85 & 6,71 & 2,02 & 7,52 & 7,92 \\
\hline $\begin{array}{l}\text { Umur Busa } \\
\text { (hari) }\end{array}$ & 6 & 3 & 1 & 16 & 1 & 1 \\
\hline $\begin{array}{l}\text { Tegangan } \\
\text { Permukaan } \\
\text { (dyne/cm) }\end{array}$ & 18,79 & 11,08 & 14,59 & 39,3 & 19,81 & 17,93 \\
\hline $\begin{array}{l}\text { Tegangan } \\
\text { Antarmuka } \\
\text { (dyne/cm) }\end{array}$ & 2,47 & 0,87 & 2,11 & 1,31 & 2,89 & 2,12 \\
\hline $\begin{array}{l}\text { Sudut } \\
\text { Kontak }\left({ }^{\circ}\right)\end{array}$ & 97,24 & 95,3 & 58,045 & 82,225 & 57,945 & 65,81 \\
\hline $\begin{array}{l}\text { Viskositas } \\
\text { (cP) }\end{array}$ & 4,68 & 1,36 & 1,81 & 1,05 & 1,06 & 1,82 \\
\hline $\begin{array}{l}\text { Densitas } \\
\left(\mathrm{g} / \mathrm{cm}^{3}\right)\end{array}$ & 1 & 1 & 1 & 1 & 1 & 1 \\
\hline
\end{tabular}

Selain beberapa parameter penting dalam pemilihan bahan baku foaming agent berdasarkan karakteristik fisik, perlu di dukung oleh pembobotan untuk mendukung hasil uji fisik yang dilakukan. Urutan pemilihan bahan baku melalui pembobotan adalah sebagai berikut [9]: 
a. Menentukan jenis bahan baku

Jenis bahan baku yang digunakan adalah Natrium (Na) Palmitat, Natrium (Na) Laurat, Natrium (Na) Oleat, Kalium (K) Palmitat, Kalium (K) Laurat, Kalium (K) Oleat.

b. Menentukan kriteria

Tabel 2 merupakan kriteria respon dan variabel dari hasil uji fisik foaming agent.

Tabel 2. Kriteria respon uji fisik foaming agent

\begin{tabular}{ll}
\hline \multicolumn{1}{c}{ Kriteria } & Variabel \\
\hline Volume Busa & $\mathrm{C} 1$ \\
Umur Busa & $\mathrm{C} 2$ \\
Tegangan Permukaan & $\mathrm{C} 3$ \\
Tegangan Antarmuka & $\mathrm{C} 4$ \\
Sudut Kontak & $\mathrm{C} 5$ \\
Viskositas & $\mathrm{C} 6$ \\
Densitas & $\mathrm{C} 7$ \\
\hline
\end{tabular}

c. Menentukan bobot dari kriteria

Nilai bobot dari kriteria ditentukan berdasarkan penilaian pakar terkait sebagai responden untuk menilai dari kriteria parameter uji yang meliputi volume busa, umur busa, tegangan permukaan, tegangan antarmuka, sudut kontak, viskositas dan densitas. Bobot dari kriteria hasil dari penilaian para pakar disajikan pada Tabel 3.

Tabel 3 Bobot dari kriteria

\begin{tabular}{llc}
\hline \multicolumn{1}{c}{ Kriteria } & Variabel & Bobot Kriteria \\
\hline Volume Busa & C1 & 23,33 \\
Umur Busa & C2 & 32,50 \\
Tegangan Permukaan & C3 & 11,67 \\
Tegangan Antarmuka & C4 & 8,33 \\
Sudut Kontak & C5 & 10,00 \\
Viskositas & C6 & 7,50 \\
Densitas & C7 & 6,67 \\
\hline
\end{tabular}

d. Menentukan bobot dari kriteria bahan baku

Seleksi bahan baku foaming agent pemadam kebakaran gambut, dapat diberi nilai bobot untuk masing-masing bahan baku dari setiap respon uji. Tabel 4 merupakan nilai kriteria bahan baku foaming agent hasil saponifikasi asam lemak minyak sawit.

Tabel 4. Kriteria jenis bahan baku

\begin{tabular}{|c|c|c|c|c|c|c|c|}
\hline \multirow{2}{*}{$\begin{array}{c}\text { Jenis Bahan } \\
\text { Baku }\end{array}$} & \multicolumn{7}{|c|}{ Nilai Kriteria } \\
\hline & $\mathrm{C} 1$ & $\mathrm{C} 2$ & C3 & $\mathrm{C} 4$ & $\mathrm{C} 5$ & C6 & $\mathrm{C7}$ \\
\hline Na Palmitat & 1,33 & 6 & 18,79 & 2,47 & 97,24 & 4,68 & $\overline{1}$ \\
\hline $\mathrm{Na}$ Laurat & 8,85 & 3 & 11,08 & 0,87 & 95,30 & 1,36 & 1 \\
\hline $\mathrm{Na}$ Oleat & 6,71 & 1 & 14,59 & 2,11 & 58,05 & 1,81 & 1 \\
\hline K Palmitat & 2,02 & 16 & 39,3 & 1,31 & 82,23 & 1,05 & 1 \\
\hline K Laurat & 7,52 & 1 & 19,81 & 2,89 & 57,95 & 1,06 & 1 \\
\hline K Oleat & 7,92 & 1 & 17,93 & 2,12 & 65,81 & 1,82 & 1 \\
\hline
\end{tabular}

e. Nilai maksimal dari setiap kriteria jenis bahan baku

Nilai maksimal dari masing-masing bahan baku disajikan pada Tabel 5, dari tabel tersebut terlihat bahwa nilai maksimal adalah $\mathrm{C5}$.

Tabel 5. Nilai maksimal dari setiap kriteria jenis bahan baku

\begin{tabular}{lc}
\hline \multicolumn{1}{c}{ Kriteria } & Nilai Maksimal \\
\hline Nilai Max C1 & 8,85 \\
Nilai Max C2 & 16 \\
Nilai Max C3 & 39,3 \\
Nilai Max C4 & 2,89 \\
Nilai Max C5 & 97,24 \\
Nilai Max C6 & 4,68 \\
Nilai Max C7 & 1 \\
\hline
\end{tabular}

f. Menentukan nilai normalisasi

Nilai normalisasi matriks didapatkan dari pembagian nilai bobot kriteria bahan baku dengan nilai maksimal kriteria jenis bahan baku, nilai matriks normalisasi disajikan pada Tabel 6 .

Tabel 6. Nilai normalisasi

\begin{tabular}{lccccccc}
\hline \multirow{2}{*}{$\begin{array}{c}\text { Alternatif } \\
\text { Bahan Baku }\end{array}$} & \multicolumn{7}{c}{ Nilai Normalisasi } \\
\cline { 2 - 8 } & C1 & C2 & C3 & C4 & C5 & C6 & C7 \\
\hline Na Palmitat & 0,15 & 0,38 & 0,48 & 0,85 & 1,00 & 1,00 & 1,00 \\
Na Laurat & 1,00 & 0,19 & 0,28 & 0,30 & 0,98 & 0,29 & 1,00 \\
Na Oleat & 0,76 & 0,06 & 0,37 & 0,73 & 0,60 & 0,39 & 1,00 \\
K Palmitat & 0,23 & 1,00 & 1,00 & 0,45 & 0,85 & 0,22 & 1,00 \\
K Laurat & 0,85 & 0,06 & 0,50 & 1,00 & 0,60 & 0,23 & 1,00 \\
K Oleat & 0,89 & 0,06 & 0,46 & 0,73 & 0,68 & 0,39 & 1,00 \\
\hline
\end{tabular}

g. Menentukan nilai maksimal

Untuk menentukan hasil akhir diperoleh dari proses perankingan, yaitu penjumlahan dari perkalian vektor bobot dengan matriks ternormalisasi sehingga diperoleh nilai terbesar yang dipilih sebagai alternatif bahan baku foaming agent terbaik. Nilai maksimal dari bahan baku foaming agent disajikan pada Gambar 1. Nilai tertinggi adalah $\mathrm{Na}$ Laurat sebesar 70,08 kemudian disusul yang ke dua adalah $\mathrm{K}$ Palmitat dengan 53, 87. Kedua bahan baku tersebut yang dipilih sebagai bahan baku foaming agent untuk aplikasi pemadaman kebakarn gambut. 


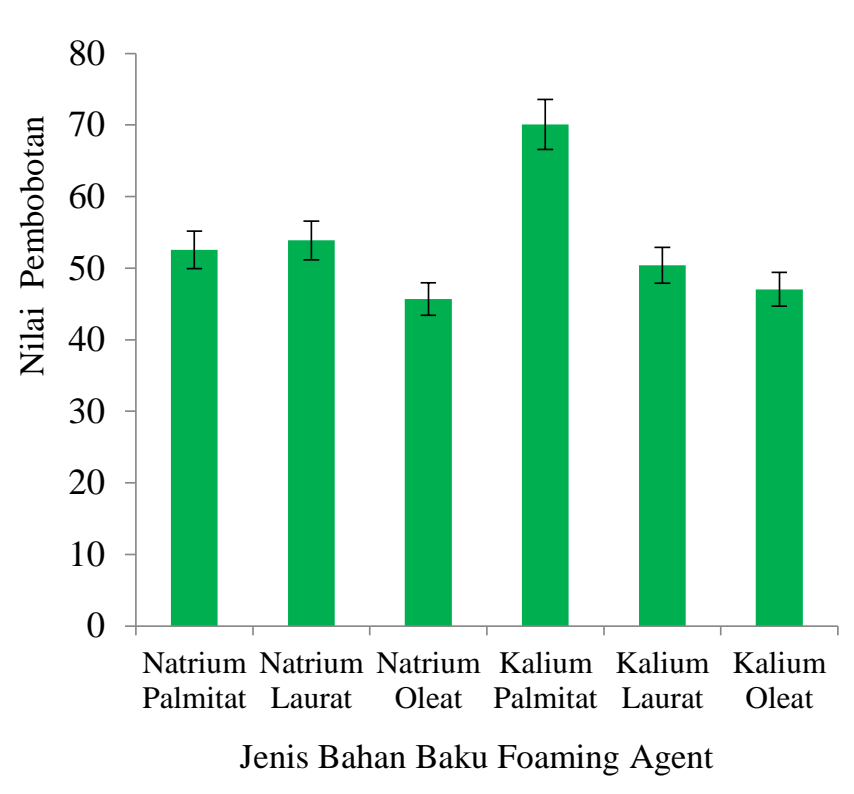

Gambar 1. Nilai pembobotan

\section{Kesimpulan}

Bahan baku foaming agent yang akan digunakan sebgai formula untuk pembuatan konsentrat pembangkit busa untuk aplikasi kebakaran gambut adalah Natrium Laurat dan Kalium Palmitat, keduanya memiliki sifat fisik yang berbeda. $\mathrm{Na}$ Laurat menghasilkan busa yang banyak dan memapu menurunkan tegangan permukaan air yang baik, sedangkan Kalium Palmitat memiliki daya tahan busa yang dihasilkan bertahan paling lama dibanding bahan lain.

\section{Penghargaan}

Ucapan terimakasih disampaikan kepada:

1. Kementrian Riset Teknologi dan Pendidikan Tinggi, atas pemberian beasiswa pendidikan dan hibah pendanaan penelitian disertasi doktor tahun 2018.

2. Badan Pengelola Dana Kelapa Sawit, Kementrian Keuangan, atas bantuan pendanaan Penelitian.

\section{Referensi}

[1]Limin, S. H., 2006. Workshop Gambut Kerjasama antara BPPT dan CIMTROP. Universitas Palangkaraya.

[2] Oguike, R. S., 2013. Study of Fire Fighting Foam Agent from Palm Oil for Extinguishing of Petrol Fires Bauchi (NG): Material Science Research Laboratory, University Bauchi, Nigeria.

[3] Japan International Cooperation Agency., 2016. Standard Operating Procedure concerning FireFighting Techniques against Peat-Land and
Forest Fires. The JICA Partnership Program for Enhancing Fire-Fighting Techniques against Peat-Land and Forest Fires in Balikpapan, Indonesia.

[4] Mizuki, H., Ueza, K. Kawano, T., Kadono, T., Kobayashi, M., Hatae, S., Oba, Y., Iwamoto, S., Mitumune, S., Nagatomo, Y., Owari, M., Umeki, H., Yamaga, K., 2007. Novel Environmental Friendly Soap-Based FireFighting Agent. J.Environ. Eng. Manage, 17, (6) 403-408 .

[5] Kawahara, T., Hatae, S., Kanyama, T., Ishizaka, I.; Uezu, K., 2016. Development of Eco-Frindly Soap-based Firefighting From for Forest Fire. Evironmental Materials and Protocols Section: Short Communication,. 54, (1) 75-78.

[6] Subekti, P., Pradesi, J., Hambali. E., 2016. Studi awal pemanfaatan bahan baku lokal untuk membuat busa ramah lingkungan sebagai pemadam api pada kebakaran Lahan gambut. Seminar Nasional Mesin dan Teknologi Kejuruan, Jakarta.

[7] Subekti, P., Hambali E., Suryani, A., P Suryadarma., 2017. Potential production of palm oil-based foaming agent as fire extinguisher of peatlands in Indonesia: Literature review. IOP Conf. Series: Earth and Environmental Science 65, 012038. do i :10.1088/1755-1315/65/1/012038.

[8]Rivai, M., Hambali, E., Suryani, A, Firmansyah, S., Pradesi, J., 2017. Synthesis of palm oil fatty acid as foaming agent for firefighting application. IOP Conf. Series Earth and Environmental Science,1265,401204.

[9] Kusumadewi, S. Hartati, A. Harjoko and R. Wardoyo., 2006. Fuzzy Multi-Attribute Decision Making (FUZZY MADM)., Graha Ilmu, Yogyakarta.

[10] Fishburn, PC., 1967. Letter to the EditorAdditive Utilities with Incomplete Product Sets: Application to Priorities and Assignments. Operations Research 15(3):537542. doi: 10.1287/opre.15.3.537.

[11] Kaliszewski, I., and Podkopaev, D., 2016. Simple Additive Weighting - a metamodel for Multiple Criteria Decision Analysis methods, Expert Systems With Applications. doi:10.1016/j.eswa.2016.01.042.

[12] Chou, SY., Chang, YH., \& Shen, CY., 2008. A fuzzy simple additive weighting system under group decision-making for facility location selection with objective/subjective attributes. European Journal of Operational Research, 189(1),132-145. doi:10.1016/j.ejor.2007.05.006. 